\title{
GATOR Complex Protein DEPDC5
}

National Cancer Institute

\section{Source}

National Cancer Institute. GATOR Complex Protein DEPDC5. NCI Thesaurus. Code C148377.

GAT OR complex protein DEPDC5 (1603 aa, 181 kDa) is encoded by the human DEPDC5 gene. This protein plays a role in the inhibition of Ras-related GT P-binding proteinmediated signaling. 